\title{
Genic regions of a large salamander genome contain long introns and novel genes
}

\author{
Jeramiah J Smith ${ }^{1,6,7}$, Srikrishna Putta1, Wei Zhu², Gerald M Pao², \\ Inder M Verma ${ }^{2}$, Tony Hunter ${ }^{2}$, Susan V Bryant ${ }^{3,4}$, David M Gardiner ${ }^{3,4}$, \\ Timothy T Harkins ${ }^{5}$ and S Randal Voss*1
}

\begin{abstract}
Address: ${ }^{1}$ Department of Biology and Spinal Cord and Brain Injury Research Center, University of Kentucky, Lexington, KY 40506, USA, ${ }^{2}$ The Salk Institute for Biological Studies, La Jolla, CA 92037, USA, ${ }^{3}$ Department of Developmental and Cell Biology, University of California Irvine, Irvine, CA 92697, USA, ${ }^{4}$ The Developmental Biology Center, University of California Irvine, Irvine, CA 92697, USA, ${ }^{5}$ Roche Applied Science, Indianapolis, IN 46250, USA, ${ }^{6}$ University of Washington, Department of Genome Sciences, Seattle, WA 98195, USA and ${ }^{7}$ Benaroya Research Institute at Virginia Mason, Seattle, WA 98101, USA

Email: Jeramiah J Smith - smithjj@u.washington.edu; Srikrishna Putta - sputt2@uky.edu; Wei Zhu - wzhu@salk.edu;

Gerald M Pao - pao@salk.edu; Inder M Verma - verma@salk.edu; Tony Hunter - hunter@salk.edu; Susan V Bryant - svbryant@uci.edu;

David M Gardiner -dmgardin@uci.edu; Timothy T Harkins - tim.harkins@roche.com; S Randal Voss* - srvoss@uky.edu

* Corresponding author
\end{abstract}

Published: 13 January 2009

BMC Genomics 2009, 10:19 doi:10.1186/1471-2164-10-19
Received: 18 July 2008

Accepted: 13 January 2009

This article is available from: http://www.biomedcentral.com/I47I-2/64/10/19

(C) 2009 Smith et al; licensee BioMed Central Ltd.

This is an Open Access article distributed under the terms of the Creative Commons Attribution License (http://creativecommons.org/licenses/by/2.0), which permits unrestricted use, distribution, and reproduction in any medium, provided the original work is properly cited.

\begin{abstract}
Background: The basis of genome size variation remains an outstanding question because DNA sequence data are lacking for organisms with large genomes. Sixteen BAC clones from the Mexican axolotl (Ambystoma mexicanum: $\mathrm{c}$-value $=32 \times 10^{9} \mathrm{bp}$ ) were isolated and sequenced to characterize the structure of genic regions.

Results: Annotation of genes within BACs showed that axolotl introns are on average 10x longer than orthologous vertebrate introns and they are predicted to contain more functional elements, including miRNAs and snoRNAs. Loci were discovered within BACs for two novel EST transcripts that are differentially expressed during spinal cord regeneration and skin metamorphosis. Unexpectedly, a third novel gene was also discovered while manually annotating BACs. Analysis of human-axolotl protein-coding sequences suggests there are $2 \%$ more lineage specific genes in the axolotl genome than the human genome, but the great majority $(86 \%)$ of genes between axolotl and human are predicted to be $1: 1$ orthologs. Considering that axolotl genes are on average $5 \times$ larger than human genes, the genic component of the salamander genome is estimated to be incredibly large, approximately 2.8 gigabases!
\end{abstract}

Conclusion: This study shows that a large salamander genome has a correspondingly large genic component, primarily because genes have incredibly long introns. These intronic sequences may harbor novel coding and non-coding sequences that regulate biological processes that are unique to salamanders. 


\section{Background}

It was established before the advent of DNA sequencing that organisms show incredible variation in genome size. This presented a paradox because scientists originally expected a positive relationship between genome size and organism complexity [1]. The paradox was partially resolved by partitioning overall genome size into two compartments: protein coding vs non-protein coding. This partition showed that organisms tend to have similar numbers of genes but non-coding and presumptively non-functional portions of genomes vary greatly [2]. In recent years, perception has changed; it is well-established that non-genic regions of genomes encode regulatory and structural information, and functional RNAs $[3,4]$. Surprisingly, almost all of the genome is transcribed in some organisms, not simply the protein-coding portion [5-7]. Some repetitive sequence classes that were thought to only selfishly expand genome size at the expense of the host are known to regulate transcription and contribute to gene evolution [8-12]. Genomes contain large non-coding regions that are conserved across species [13-15], and lineage-specific, non-coding DNA between distantly related species is associated with the same regulatory functions; such patterns are consistent with non-coding DNA having a regulatory function $[16,17]$. Finally, the amount of non-coding DNA does scale with developmental complexity in some comparative studies [18]. These findings are motivating renewed interest into genome diversity and function. Unfortunately, DNA sequence data are completely lacking for organisms with large genomes.

In this study, 454 DNA sequencing was used to obtain the first glimpse of a salamander genome. The Mexican axolotl (Ambystoma mexicanum) was selected because it is a model organism with an average-sized salamander genome: $\sim 32 \times 10^{9}$ bp distributed among 14 haploid chromosomes [19]. Considering the possibility of extensive repetitive DNA tracts in the axolotl genome that would confound downstream sequence assembly, it was reasoned that genic regions of the genome would be less likely to contain repetitive DNA. Also, recent analyses suggest that regulatory elements within the human genome tend to be associated with the location of known genes [20]. Thus, a partial BAC library was developed and PCR screening identified 16 clones that contain expressed sequence tags (ESTs) [21]. This allowed direct comparison of orthologous genic regions between axolotl and the human genome and analysis of two BACs that contained presumptively novel axolotl transcripts. To complement this approach, computational analyses were used to search existing EST databases for genes that are specific to axolotls and perhaps other amphibians. The results from these analyses, discussed below, begin to address the basis of the axolotl's large genome size and the significance of excess DNA in genic regions.

\section{Results \\ BAC sequence assembly and annotation}

A small BAC library (36,864 clones) was constructed and screened by PCR to identify 16 clones that contained coding sequences for previously identified ESTs (Table 1). Altogether, these clones span more than 1.7 megabases (non-redundant) of the axolotl genome. BAC clones were end-sequenced using the ABI-Sanger method and then 454 sequencing technology was used to generate several thousand, high quality sequence reads for each clone (Table 2). Sequence assembly statistics (N50 and average sequence coverage) indicate that high quality assemblies were generated for each BAC; seven BAC assemblies yielded a single long contig and three $\mathrm{BAC}$ assemblies yielded two contigs separated by single gaps. The sequence coverage provided by the assemblies approximated the estimated size of BAC clones on agarose gels (data not shown). The remaining assemblies consisted of 6 or fewer large contigs. The reason why a few contigs yielded incomplete assemblies is not clear because different numbers of high quality reads were obtained for each BAC and contig numbers within assemblies were not correlated with sequencing depth. However, in only one case was it clear (while editing and annotating contigs) that repetitive sequences confounded contig assembly of a BAC (clone H3_4F24). Indeed, very few repetitive DNA sequences were identified overall within axolotl BACs, with retrotransposons representing the largest fraction (Table 3). These results suggest that genic regions of the axolotl are not completely structured by repetitive sequences. Annotated BAC assemblies have been deposited in GenBank [GenBank: EU686400-EU686415].

\section{Introns and exons within BACs}

To further investigate the structure of genic regions within the axolotl genome, introns and exons were identified within BACs and compared to orthologous sequences from humans. BLAST analysis confirmed the presence of targeted EST sequences within 14 of 16 BAC assemblies. The length of orthologous coding sequences between axolotl and humans is highly conserved, as is the location of exon/intron boundaries (Table 1; Additional file 1). However, axolotl introns are strikingly longer than human introns: within five genes for which orthology could be firmly established, axolotl introns average 9454 bp while human introns average only 1938 bp $(\mathrm{N}=32$ introns compared). Further comparisons show that axolotl introns are approximately $14 \times$ larger than orthologous introns from chicken $(\mathrm{N}=32)$ and $12 \times$ larger than orthologous introns from Xenopus tropicalis $(\mathrm{N}=25$; purinergic receptor P2X3 was not identified in the X. tropicalis assembly) (Additional file 1, Figure 1). Thus, non-coding genic regions are contributing significantly more to axolotl genome size than they are to vertebrates with "averagesized" genomes. 
Table I: Identity and structure of genes within BACs

\begin{tabular}{|c|c|c|c|c|c|}
\hline BAC & Ambystoma Sequence & Presumptive Human Ortholog & $\begin{array}{l}\text { Complete Axolotl } \\
\text { ORF? }\end{array}$ & $\begin{array}{l}\text { Introns } \\
\text { Identified }\end{array}$ & $\begin{array}{l}\text { Exons } \\
\text { Identified }\end{array}$ \\
\hline H3_ID2 & Tig_NM_4343_Contig_I & NP_004334.I calreticulin precursor & Complete & 8 & 9 \\
\hline H3_4AII & Mex_Nohits_2574_Contig_I & Unknown & Complete & $9 c$ & 10 \\
\hline H3_4F24 & Tig_NM_362_Contig_I & $\begin{array}{l}\text { NP_003247.I tissue inhibitor of metalloproteinase } 4 \\
\text { precursor }\end{array}$ & Unknown & $I^{c}$ & $3 e$ \\
\hline H3_37III & Tig_NM_7006_Contig_I & $\begin{array}{l}\text { NP_008937.I cleavage and polyadenylation specific } \\
\text { factor } 5\end{array}$ & Partial & 5 & 6 \\
\hline H3_37I23 & Tig_NM_18948_Contig_I & NP_061821.I mitogen-inducible gene 6 protein & Complete $^{\mathrm{a}}$ & - & 1 \\
\hline H3_37N9 & Mex_Nohits_697_Contig_I & NP_07I436.I platelet receptor Gi24 & Partial & 5 & 5 \\
\hline H3_4IL2I & Mex_NM_687_Contig_I & NP_000678.I S-adenosylhomocysteine hydrolase & Pseudogene ${ }^{b}$ & - & - \\
\hline $\mathrm{H} 3 \_46 \mathrm{HIO}$ & Tig_NM_1428_Contig_I & NP_00I4I9.I enolase I & Partial & - & 1 \\
\hline H3_48F8 & Tig_NM_859_Contig_I & $\begin{array}{l}\text { NP_000850.I 3-hydroxy-3-methylglutaryl- } \\
\text { Coenzyme A reductase }\end{array}$ & Complete & 14 & 15 \\
\hline $\mathrm{H} 3 \_48 \mathrm{~K} 23$ & Mex_NM_20169_Contig_4 & NP_996846.I retinoic acid receptor responder & Partial & $I^{c}$ & 2 \\
\hline $\mathrm{H} 3 \_6 \mathrm{ICI}$ & Mex_Nohits_22I_Contig_2 & Unknown & Complete & - & 1 \\
\hline $\mathrm{H} 3 \_6 \mathrm{IK} 9$ & Mex_NM_5032_Contig_2 & NP_005023.2 plastin 3 & Partial & 1 & 2 \\
\hline $\mathrm{H} 3 \_62 \mathrm{O} 2 \mathrm{I}$ & Mex_NM_18947_Contig_If & NP_002550.2 purinergic receptor $\mathrm{P} 2 \mathrm{X} 3$ & Partial & 7 & 8 \\
\hline H3_67LI5 & Tig_NM_4343_Contig_I & NP_004334.I calreticulin precursor & Complete & $8^{e}$ & 9 \\
\hline H3_7IA8 & Tig_NM_I825I3_Contig_I & $\begin{array}{l}\text { NP_ } 872319.1 \text { spindle pole body component } 24 \\
\text { homolog }\end{array}$ & False positive & - & - \\
\hline H3_7IDI5 & Mex_NM_6276_Contig_2 & $\begin{array}{l}\text { NP_001026854.I splicing factor, arginine/serine-rich } \\
7,35 \mathrm{kDa}\end{array}$ & Complete $^{a}$ & - & 1 \\
\hline
\end{tabular}

$a$ - start codon was not identified, but it is likely present in assembled sequence. $b$ - this BAC contains a presumptive processed pseudogene. The aligning BAC and cDNA sequence are $91 \%$ identical and the BAC sequence contains no introns. $c-$ not used in multispecies alignments due to lack of obvious vertebrate orthologies. $d$ - exons were identified on two different contigs. e - not considered in multispecies alignments due to redundancy with H3_ID2. $\mathrm{f}$ - contig was originally identified as cytochrome c.

\section{Composition of axolotl introns}

It is possible that axolotl introns are large because they contain DNA sequence classes that are unique or over-represented in comparison to other vertebrates. To test this idea, all axolotl introns and orthologous human introns were searched for self-similarity, repetitive DNAs (transposons and retrotransposons), and non-coding RNAs (including miRNAs and snoRNAs). Examination of individual self-self intron alignments and alignment of the concatenated intron dataset revealed that axolotl introns do not contain extensive tracts of repetitive DNA and are composed of largely unique sequence (Additional files 2 and 3). Multiple retroelement types were identified in axolotl introns in the selected genes but none were identified in the orthologous human introns (Table 3). Although the human genome contains many repeat classes, the only repeats identified in this sample of human introns were DNA transposons. The proportion of nucleotides accounted for by interspersed repetitive sequences is significantly higher in axolotl introns, relative to human introns $(1.82 \%$ vs. $0.38 \%, \mathrm{Z}=25.6$, $\mathrm{p}<<$ 0.0001 ). A total of 70 candidate miRNA precursors and 21 snoRNAs (16 HACA type snoRNAs and 5 CD type snoRNAs) were identified from sense DNA strands of the axol- 
Table 2: Summary statistics for axolotl BAC sequencing and assembly

\begin{tabular}{lllll}
\hline Total Assembly Length (bp) & Number of Contigs & N50 Length (bp) & Sequences Covering BAC & Avg. Seq. Coverage \\
\hline 102210 & 1 & 102210 & 9777 & 24.51 \\
137463 & 1 & 137463 & 11218 & 20.27 \\
123412 & 6 & 21185 & 9033 & 23.44 \\
113164 & 2 & 56755 & 9036 & 22.39 \\
137255 & 4 & 51165 & 9238 & 12.78 \\
118832 & 2 & 51165 & 8882 & 18.57 \\
117549 & 1 & 117549 & 9049 & 19.83 \\
120452 & 3 & 48654 & 5323 & 12.76 \\
120467 & 1 & 120467 & 6120 & 13 \\
125197 & 6 & 31049 & 2093 & 6.55 \\
99252 & 2 & 51540 & 7858 & 19.82 \\
102224 & 1 & 102224 & 6448 & 16.08 \\
113103 & 1 & 113103 & 7360 & 15.99 \\
110421 & 3 & 67330 & 3833 & 9.01 \\
114195 & 41502 & 12090 & 27.65 \\
108550 & 1 & 108550 & 7159 & 16.58 \\
\hline
\end{tabular}

otl (Additional files 4 and 5). The miRNAs totaled $7 \mathrm{~kb}$ and the snoRNAs totaled $2.7 \mathrm{~kb}$ for a total contribution of $2.7 \%$ to overall intron length. By way of comparison, computational searches of 39 orthologous human introns (58,313 bp) identified 6 candidate miRNAs, 1 CD type snoRNA, and no candidate HACA type snoRNAs (Additional files 4 and 5); none of these human introns contain annotated miRNAs or snoRNAs within the current human genome assembly [22]. Thus, the density of predicted small, intronic ncRNAs is significantly higher in axolotls than in humans (Table 4). These analyses show that axolotl introns contain a greater diversity of transposable ele-

Table 3: Percentages of repetitive elements within BACs and introns

\begin{tabular}{llll}
\hline & \multicolumn{2}{c}{ Axolotl } & Human \\
\cline { 2 - 3 } & BACs & Introns & Introns \\
\hline Total interspersed: & 2.32 & 1.82 & 0.38 \\
& & & \\
Total retroelements: & 2.24 & 1.72 & 0 \\
SINEs: & 0 & 0 & 0 \\
LINEs: & 0.29 & 0.25 & 0 \\
L2/CRI/Rex & 0.11 & 0.16 & 0 \\
RI/LOA/Jockey & 0 & 0 & 0 \\
RTE/Bov-B & 0.01 & 0.01 & 0 \\
LI/CIN4 & 0.18 & 0.07 & 0 \\
LTR elements: & 1.95 & 1.47 & 0 \\
Gypsy/DIRSI & 1.42 & 0.78 & 0 \\
Retroviral & 0.24 & 0.37 & 0 \\
& & & \\
DNA transposons: & 0.08 & 0.1 & 0.38 \\
Hobo-Activator & $<0.01$ & 0.05 & 0 \\
PiggyBac & 0 & 0 & 0.18 \\
Tourist/Harbinger & 0.06 & 0.04 & 0 \\
& & &
\end{tabular}

ments and potentially functional DNA sequence elements than human introns.

The high density of predicted miRNA structures within axolotl introns could be an artifact of the methods that were used to identify candidate miRNAs, or could represent other complex hairpin sequences that do not enter miRNA processing. To investigate this further, predicted miRNA sequences were aligned to 773,450 small RNA sequences that were recently characterized from amputated and regenerating axolotl limbs (unpublished data). This new axolotl miRNA database will be described elsewhere. Two of the predicted miRNAs from axolotl introns had stem regions that aligned perfectly with mature miRNA sequences from the axolotl limb miRNA database (Figure 2): AMmiRNA16 aligned to a single $24 \mathrm{bp}$ sequence and AMmiRNA23 aligned to three independently sampled 26 bp sequences. These perfect alignments suggest that some of the predicted elements within axolotl introns are likely to be bona fide miRNA genes.

\section{Novel genes}

Two of the BACs in this study were selected because they contain transcripts with no known homolog in other vertebrates (Table 1). Results from microarray analyses predict a role for these "no-hit" EST contigs in two unique salamander developmental processes: metamorphosis and regeneration. The no-hit transcript that is encoded on H3_4A11 (Mex_Nohits_2574_Contig_1) is significantly downregulated during spinal cord regeneration, while the no-hit transcript that is encoded on H3_61C19 (Mex_Nohits_221_Contig_2) is significantly upregulated during spinal cord regeneration and downregulated during skin metamorphosis $[23,24]$. Although some no-hit ESTs are truncated versions of known genes, it is possible that many of the 2000 no-hit transcripts in the 


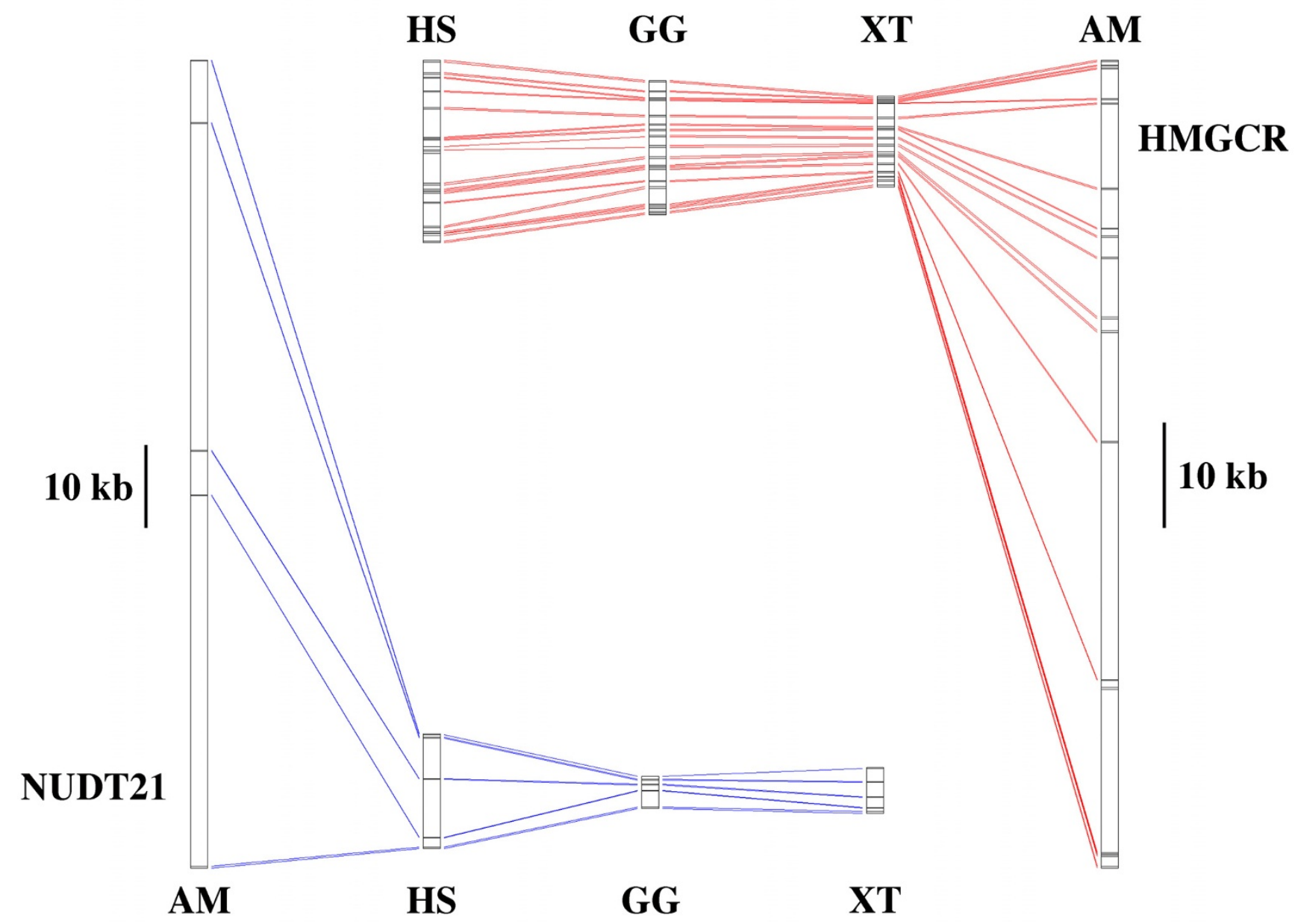

\section{Figure I}

Comparison of intron lengths among the axolotl (AM), human (HS), chicken (GG), and frog Xenopus tropicalis (XT) for cleavage and polyadenylation specific factor 5 (NUDT2I) and 3-hydroxy-3-methylglutaryl-Coenzyme A reductase (HMGCR). One exon of HMGCR could not be identified in the $X$ tropicalis genome.

Ambystoma EST database correspond to novel axolotl genes. Annotation of axolotl no-hit EST/BAC alignments supports the later hypothesis. Two novel genes, Axnovel_1 and Axnovel_2, were identified within H3_4A11 and H3_61C19, respectively. These novel genes correspond to the no-hit transcripts described above. Unexpectedly, a group of no-hit ESTs aligned to a second region of

Table 4: Densities of predicted non-coding RNAs identified within salamander BACs and human orthologous introns

\begin{tabular}{lcccc}
\hline Predicted ncRNAs & Ambystoma & Human & Z & P-value \\
\hline miRNA & $1.6 \%$ & $1.0 \%$ & 11.1 & $<<1 \mathrm{e}-4$ \\
snoRNA & $0.6 \%$ & $0.1 \%$ & 15.0 & $<<1 \mathrm{e}-4$ \\
Total & $2.3 \%$ & $1.2 \%$ & 17.4 & $<<l e-4$ \\
\end{tabular}

H3_4A11 that is distinct from Axnovel_1. These alignments predict a third novel gene (Axnovel_3) that has introns and is spliced (Figure 3). None of these three genes show sequence similarity to any known vertebrate gene.

To determine if these novel genes encode proteins or noncoding RNAs, EST/BAC sequence alignments were manually curated and searched for open reading frames (ORFs) using ORF finder at NCBI [25]. In all three cases the longest ORF was oriented 5' to 3 ' relative to the EST sequences. Axnovel_2 and Axnovel_3 can be translated into long ORFs (Axnovel_2 - 786 bp and Axnovel_3 - $360 \mathrm{bp}$ ) that are initiated with a start methionine and terminated by a stop codon. Manual curation of Axnovel_3 revealed several small exons that were not identified by automated 


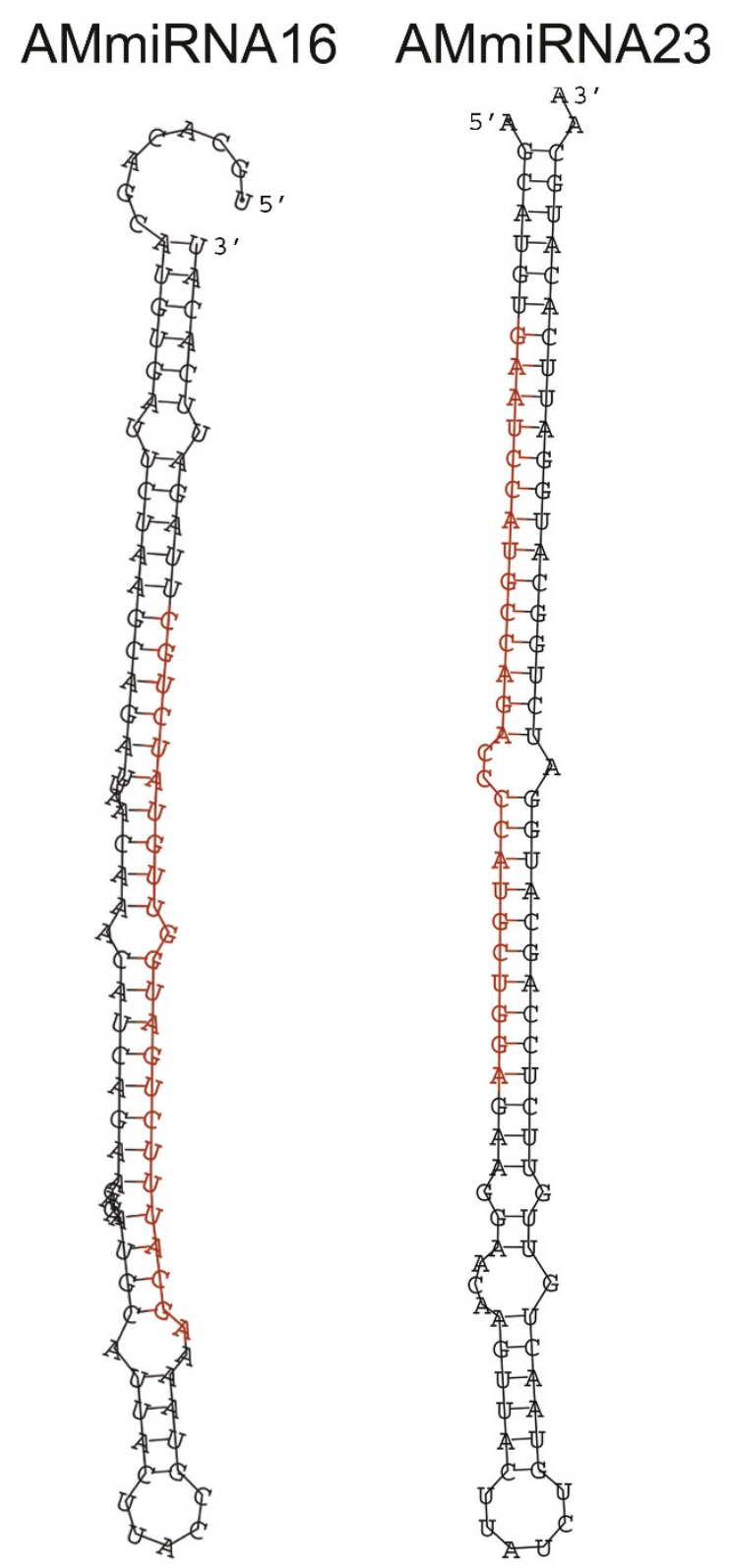

Figure 2

Structure of two A. mexicanum miRNAs (AMmiRNA 16, AMmiRNA23) that were predicted from axolotl introns. The red bases indicated positions where the predicted miRNA sequences show complete identify to small RNAs isolated from regenerating limbs.

sequence alignments (Figure 3 ). The coding sequence spans eight small 5 ' exons that range in length from 21 to $60 \mathrm{bp}$ and extends 48 bp into a longer 3' exon that contains the presumptive 3' UTR of this gene. Nearly the entire length of Axnovel_1 (249 of 313 bp) can be translated into a single ORF with a stop codon. The only in-

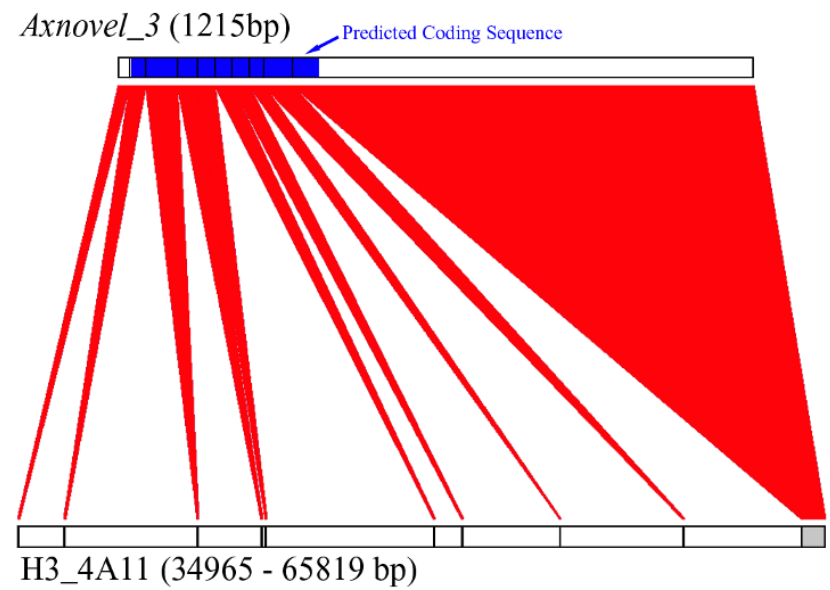

Figure 3

Intron-exon structure of a novel axolotl salamander gene (AxNovel_3) discovered within BAC H3_4AII. Intron/Exon boundaries are represented by vertical black bars. The predicted coding sequence for AxNovel_3 is shaded in blue. Red figures join the relative locations of sequences in the transcript and genomic sequence.

frame methionine codon is located in the middle of the ORF, however the first codon of the longest ORF is CTG, so it is possible that this gene uses an alternative CUG start codon [26]. Interestingly, orthologous EST sequences have also been sampled for Axnovel_1 in A. tigrinum tigrinum, a close relative. The A. $t$. tigrinum contig shares $>98 \%$ nucleotide identity with Axnovel_1 and also encodes a 5' CUG. It is unclear if Axnovel_1 is translated into a functional protein or if it functions as a ncRNA; however maintenance of gene structure and sequence identity between salamander species that diverged several million years ago supports the idea that it is functional.

The most likely mechanism for the origin of novel, functional genes in the Ambystoma genome is gene duplication, as there is no evidence for whole genome duplication in A. mexicanum. It is important to consider the possibility that the large Ambystoma genome may have been shaped by a higher rate of gene duplication and fewer gene losses, and thus contain a greater overall number of genes. If paralogous loci are abundant in the Ambystoma genome, then many salamander genes are expected to show relatively more, many-to-one orthology relationships with genes from other vertebrates. To test this hypothesis, paralogs were predicted for a high quality, human-salamander ortholog dataset $(\mathrm{N}=577)$, wherein primary axolotl orthologs were required to cover $>89 \%$ of the annotated length of each primary human ortholog. Approximately $86 \%(\mathrm{~N}=498)$ of the human-axolotl gene pairs in this dataset were predicted to be 1:1 orthologs (Additional file 6). Many: many ortholog groups were 
predicted for 15 human-axolotl gene sets (Additional file 7) and include members from gene families that are notorious for gene duplication and gene conversion events (e.g. globins, tubulins, and actins). Of the remaining gene pairs, 2.6x more paralogs were predicted for axolotl primary orthologs (Additional files 8 and 9). Specifically, one or more human paralogs correspond to 25 human primary orthologs, yielding 32 different paralogs overall. In comparison, 39 primary axolotl orthologs correspond to 84 different axolotl paralogs. The list of axolotl specific paralogs include annexin $A 1(\mathrm{~N}=4)$, ferritin heavy polypeptide $(\mathrm{N}=4)$, H3 histone family $3 A(\mathrm{~N}=3)$, calmodulin $2(\mathrm{~N}$ $=2)$, and matrix metalloproteinase $1(\mathrm{~N}=2)$. The largest number of axolotl paralogs $(\mathrm{N}=28)$ was identified for paternally expressed 10 isoform RF1 (peg10), an imprinted mammalian gene that shows sequence similarity to retrotransposons. As these axolotl paralogs exhibit higher sequence similarity to fish pol polyproteins [27] than human peg10, they probably correspond to an active retrotransposon family in the axolotl genome. Overall, these data predict $2 \%$ more duplicated loci in the axolotl genome versus the human genome (39/577 vs. 25/577), and more paralogs are predicted on average for axolotl duplicated loci (2.3 vs. 1.3). These estimates support the hypothesis of more lineage specific genes in the axolotl genome than the human genome. Assuming these genes also contain longer introns, the genic portion of the axolotl genome is predicted to exceed the total genome size of some vertebrates (see below).

\section{Discussion}

Comparative DNA sequence data are needed from large genomes to better understand structural and functional features that influence genome size evolution. This study demonstrates that DNA sequence data can be sampled efficiently from the large genome of the Mexican axolotl using 454 DNA sequencing. It was possible to assemble de novo short-DNA sequence reads (50-300 bp) from shot gun sequenced BACs into complete contigs, and then use this information to reveal the structure of genic regions of the genome. The results show that axolotl genic regions encode novel genes and make a significant contribution to genome size. In particular, axolotl introns are 5-10x longer than introns in other vertebrates and this maybe typical of salamander genomes [28].

Many different ideas have been proposed to explain genome size variation among organisms. The simplest explanation is a change in the ratio of DNA that codes for proteins versus non-protein coding DNA [29]. Although variation in gene number maybe important, this distinction is too simple because non-protein coding DNA has been shown in recent years to encode a diversity of functional elements. For example, protein-coding sequences (exons) are associated with introns that encode a diversity of regulatory elements and non-coding RNAs that affect transcription, translation, and chromatin structure [3032]. In order to understand the relationship between genome size and regulatory complexity, it is therefore critical to consider the proportion of DNA that resides in transcribed (genic) versus non-transcribed (i.e. intergenic) DNA. Changes in genome size that occur over relatively short evolutionary timeframes may not result in a correlated expansion of genic regions (i.e. introns), presumably due to greater evolutionary consrtaint $[33,34]$. However, positive correlations are observed between genome size and the number and length of introns at a broader evolutionary scale [35-37]. Correlations observed at this broader scale are presumably the outcome of drift and selection as population sizes and functional constraints fluctuate over millions of generations [37]. Salamanders are particularly interesting in this regard because they present a situation wherein large genomes are the rule rather than the exception. Very large genomes have likely been maintained within this group at least since the divergence of the ancestral salamander lineage $>160$ million years ago $[38,39]$. Thus, salamanders can provide novel insight into the evolutionary potential of vertebrate genomes over deep, evolutionary time.

At this point we can only speculate about the reasons why large introns evolved in A. mexicanum. In general, introns tend to be longer in genes that have tissue specific or developmentally relevant functions, than introns in house keeping or widely expressed genes [40-42]. This pattern may reflect evolution of complex transcriptional regulatory mechanisms [43-46]. It is possible that salamanders maintain large introns in-part because they encode information necessary to accomplish unique developmental processes. In particular, salamanders are capable of complex tissue regeneration, and a single genome can express both a metamorphic and paedomorphic outcome $[47,48]$. These processes involve transcriptional activation and silencing of thousands of genes that may depend upon transcriptional binding sites and ncRNAs within introns. That large salamander introns might have a functional role is supported by the absence of shared repetitive sequences among introns and the prediction of numerous miRNA and snoRNA genes in axolotl introns. It is also possible that long introns indirectly moderate cellular and developmental processes by influencing transcription and mitotic rates $[49,50]$. We note that the predicted repetitive DNAs and ncRNAs only account for a small proportion of total intron size. Characterization of additional axolotl genes, and in particular genes that function in regeneration and metamorphosis, will help optimize searches for other functional and structural elements (e.g. matrix attachment sites or unknown functional classes) that are associated with large intron size, including "junk" DNA. 


\section{Conclusion}

Results from this study show that the genic compartment of the Ambystoma genome is incredibly large. Our analysis suggests that genes in the axolotl genome are $5 \times$ larger than they are in humans and conservative estimation of lineage specific genes predicts more genes in the salamander genome than the human genome. If there are approximately $2 \%$ more genes in the axolotl genome than a 20,000 gene estimate for the human genome, and each salamander gene is on average $5 \times$ larger than a 27 kilobase average estimate for human genes [51], the genic portion of the Ambystoma genome is estimated to be a staggering 2.8 gigabases! Thus, the large salamander genome is not simply large because of excess, repetitive DNA; the genic component is also correspondingly large. Equally staggering is the fact that our estimate of genic content only accounts for $1 / 12^{\text {th }}$ of the total genome size of 32 gigabases. Even if considerably more genes are discovered to be novel in the axolotl genome, using more aggressive computational approaches to identify highly divergent proteins, this is not likely to solve the mystery of large genome size in salamanders. Additional, DNA sequencing is needed to solve this mystery and this study shows that new sequencing technologies allow such datasets to be readily generated for organisms with large genomes.

\section{Methods}

\section{BAC library construction and screening}

A BAC Library was constructed from partially digested and size selected genomic DNA that was isolated from the erythrocytes of a single A. mexicanum female. Methods for DNA isolation and BAC library construction followed [52]. 36,864 colonies were robotically picked into ninetysix 384 well plates. BAC pools were constructed and screened by PCR with 96 EST primer sets to identify 16 BACs that contained protein-coding loci.

\section{Sequencing, assembly, and annotation}

DNA was isolated for each of the 16 BAC from $200 \mathrm{ml}$ of overnight culture using a Plasmid Maxi Kit (Qiagen). All of the BACs were sequenced in a single 454 GS20 sequencing run, on one plate that was divided into subregions using a sixteen-lane gasket. Clones were also end sequenced using BigDye 3.1 chemistry and electrophoresis on an ABI capillary sequencer. Sequences were screened by Crossmatch [53] to remove vector (pCC1BAC), contaminating E. coli sequences (NC_002695.1), and additional contaminating sequences (gis:146575, 215104, 469217, 520486, 2501752) that were identified by a preliminary search of all BAC sequences against the NCBI nr database. After automated assembly using Phrap [53] (force level $=1$, all other parameters set to default), all contigs over $10 \mathrm{~kb}$ were aligned to one another to identify contigs that contained presumptively overlapping sequence. These were visually inspected using SeqMan (DNASTAR Lasergene) and manually joined when appropriate. Contiguous sequences of assembled BACs were searched (blastn) [54] against the complete set of all known salamander transcripts at Sal-Site [55] and human RefSeq (blastx and tblastp) [56] to identify and annotate gene regions within BACs. For multispecies comparisons, the locations of orthologous intron breaks were identified by aligning (blat) [57] human RefSeq proteins to genome sequence of human (Build 36.2), chicken (galGal3), X. tropicalis (xenTro2), and salamander (current study). Self/self and all $v$ s. all alignments of salamander intron sequences were performed using the program dottup (EMBOSS package) [58].

\section{Identification of repetitive elements and candidate miRNAs and snoRNAs}

427,188 bp of sequence from 48 axolotl introns was searched using several algorithms. Salamander BACs, predicted introns, and orthologous introns were searched for known repetitive elements using RepeatMasker [59] and libraries of known repeat elements [60]. Candidate miRNAs and snoRNAs were identified on the basis of predicted structural motifs within intronic regions of BACs. To identify candidate miRNAs, BAC sequences were searched using the program ProMiR II [61]. These candidate miRNAs were further tested for probable functionality using the program MiPred [62]. Candidate snoRNAs were identified using CDSeeker and ACASeeker functions of snoSeeker [63], with "modified site" files containing known human methylation and pseudouridine sites.

\section{Identification of orthologous and paralogous genes}

Reciprocal best-Blastx searching between the Ambystoma EST assembly and human RefSeq databases identified primary ortholog pairs between A. mexicanum and human. To ensure that axolotl EST contigs yielded a high quality dataset for paralog prediction, the analysis was limited to 577 ortholog pairs in which primary A. mexicanum orthologs were required to cover $>89 \%$ of the annotated length of each primary human ortholog. This limited the analysis to relatively short genes whose overall lengths have been conserved during evolution. The axolotl EST contigs were assembled previously using PaCE [64] and CAP3 [65] using a 90\% nucleotide identity threshold to assemble ESTs into contigs [21]. Singleton contigs were excluded from the analysis. Orthologous relationships were determined using an informatics approach followed by manual annotation. The conservative Inparanoid approach $[66,67]$ was used first to identify presumptive orthologs and paralogs. Primary A. mexicanum orthologs were searched (blastx) against all A. mexicanum contigs [55] and human primary orthologs were searched (blastx) against all human RefSeq entries [56]. If these within species searches identified amino acid sequences that were 
more similar to the primary ortholog, relative to the between species comparison, they were tentatively considered lineage specific paralogs. This parsed human/A. mexicanum primary orthologs among 1:1, 1: many, many: 1 , or many: many orthology classifiers. This analysis predicted 178 axolotl paralogs and 62 human paralogs. To complement the Inparanoid approach, A. mexicanum primary orthologs were searched (blastn) against EST contigs that have been assembled for a close relative: A. t. tigrinum. If 2 or more A. t. tigrinum genes were found to reciprocally best match a primary $A$. mexicanum ortholog and significantly similar A. mexicanum contigs, the A. mexicanum primary ortholog was considered a duplicated locus and the corresponding A. mexicanum contigs were considered paralogs. This approach verified 19 of the Inparanoid predictions for axolotl paralogs and suggested 18 novel paralogs that were not predicted by Inparanoid. Because the approaches described above do not: 1) differentiate paralogs from splice variants, 2) evaluate the quality of EST contigs, or 3 ) identify all paralogs, it was necessary to manually inspect the quality of all overlapping sequence alignments for presumptive 1:1 orthologs and paralogs. As a result of manual annotation, approximately $50 \%$ of the predicted human and axolotl paralogs were discarded and 4 of the 1:1 orthologs were re-classified as duplicated axolotl loci (anterior gradient 2 homolog, integral membrane protein $2 b$, stress-associated endoplasmic reticulum protein 1 , and parvalbumin). We note that axolotl gene sequences in this analysis are substantially under sampled by comparison to the known list of human gene sequence. This sampling difference is expected to yield a minimum estimate of the true abundance of axolotl/amphibian paralogs.

\section{Abbreviations}

BAC: bacterial artificial chromosome; EST: expressed sequence tag; miRNA: micro RNA; snoRNA: small nucleolar RNA; ncRNA: non-coding RNA; ORF: open reading frame.

\section{Authors' contributions}

JJS and SRV drafted the manuscript. All authors participated in acquisition, analysis, and interpretation of the data. All authors participated in critical revision of the manuscript.

\section{Additional material}

\section{Additional file 1}

Comparative data for exons and introns. A table containing exon alignment statistics and corresponding intron lengths for salamander, human, chicken, and frog.

Click here for file

[http://www.biomedcentral.com/content/supplementary/1471-

2164-10-19-S1.xls]

\section{Additional file 2}

Self-self sequence alignments. Plots showing representative self-self sequence alignments for the 4 longest introns that were isolated from $\mathrm{A}$. mexicanum.

Click here for file

[http://www.biomedcentral.com/content/supplementary/1471-

2164-10-19-S2.doc]

\section{Additional file 3}

Alignment of all salamander introns. A plot showing the self-alignment of concatenated intronic sequence sampled from A. mexicanum. Click here for file

[http://www.biomedcentral.com/content/supplementary/14712164-10-19-S3.doc]

\section{Additional file 4}

miRNAs predicted for axolotl and human. A table containing positional and statistical information for miRNAs predicted for axolotl and human. Click here for file

[http://www.biomedcentral.com/content/supplementary/14712164-10-19-S4.xls]

\section{Additional file 5}

snoRNAs predicted for axolotl and human. A table containing positional and statistical information for snoRNAs predicted for axolotl and human.

Click here for file

[http://www.biomedcentral.com/content/supplementary/14712164-10-19-S5.xls]

\section{Additional file 6}

Human-axolotl 1: 1 orthologs. A table containing identities and alignment summary statistics for human-axolotl 1: 1 orthologs.

Click here for file

[http://www.biomedcentral.com/content/supplementary/14712164-10-19-S6.xls]

\section{Additional file 7}

Human-axolotl many: many paralogs. A table containing identities and alignment summary statistics for human-axolotl many: many paralogs predicted for both human and axolotl.

Click here for file

[http://www.biomedcentral.com/content/supplementary/14712164-10-19-S7.xls]

\section{Additional file 8}

Human-axolotl many: 1 paralogs. A table containing identities and alignment summary statistics for human-axolotl many: 1 paralogs predicted for both human and axolotl.

Click here for file

[http://www.biomedcentral.com/content/supplementary/14712164-10-19-S8.xls]

\section{Additional file 9}

Human-axolotl 1: many paralogs. A table containing identities and alignment summary statistics for human-axolotl 1: many paralogs predicted for both human and axolotl.

Click here for file

[http://www.biomedcentral.com/content/supplementary/14712164-10-19-S9.xls] 


\section{Acknowledgements}

This project was supported by grants R24-RR0I6344 and P20-RR0I674I from the National Center for Research Resources (NCRR), a component of the National Institutes of Health (NIH). Its contents are solely the responsibility of the authors and do not necessarily represent the official views of NCRR or NIH. The project was also supported by a Roche genome sequencing award and funding from the California Institute for Regenerative Medicine, University of Kentucky College of Arts and Sciences and Biology Department, and Kentucky Bioinformatics Research Infrastructure Network. The Spinal Cord and Brain Injury Research Center and the National Science Foundation supported Ambystoma Genetic Stock Center (DBI-0443496) provided resources and facilities.

\section{References}

I. Thomas CA: The genetic organization of chromosomes. Ann Rev Genet 1971, 5:237.

2. Cavalier-Smith T: Cell volume and the evolution of eukaryote genome size. In The Evolution of Genome Size Edited by: CavalierSmith T. Chichester: John Wiley \& Sons; 1985:105-184.

3. Wray GA: The evolutionary signficance of cis-regulatory mutations. Nat Rev Genet 2007, 8:206-2I6.

4. Amaral PP, Mattick JS: Noncoding RNA in development. Mamm Genome 2008 in press.

5. Kapranov P, Cheng J, Dike S, Nix DA, Duttagupta R, Willingham AT, Stadler PF, Hertel J, Hackermueller J, Hofacker IL, Bell I, Cheung E, Drenkow J, Dumais E, Patel S, Helt G, Ganesh M, Ghosh S, Piccolboni A, Sementchenko $V$, Tammana $H$, Gingeras TR: RNA maps reveal new RNA classes and a possible function for pervasive transcription. Science 2007, 3 16: |484-| 488.

6. Kapranov P, Willingham AT, Gingeras TR: Genome-wide transcription and the implications for genomic organization. Nat Rev Genet 2007, 8:4I3-423.

7. Wu JQ, Du J, Rozowsky J, Zhang Z, Urban AE, Euskirchen G, Weissman S, Gerstein M, Snyder M: Systematic analysis of transcribed loci in ENCODE regions using RACE sequencing reveals extensive transcription in the human genome. Genome Biol 2008, 9:R3.

8. Singer SS, Mannel DN, Hehlgans T, Brosius J, Schmitz J: From "junk" to gene: curriculum vitae of a primate receptor isoform gene. I Mol Biol 2004, 341:883-886.

9. Hasler J, Strub K: Alu elements as regulators of gene expression. Nucleic Acids Res 2006, 34:549|-5497.

10. Bejerano G, Lowe CB, Ahituv N, King B, Siepel A, Salama SR, Rubin $E M$, Kent WJ, Haussler D: A distal enhancer and an ultraconserved exon are derived from a novel retroposon. Nature 2006, 44I:87-90.

II. Piriyapongsa J, Marino-Ramirez L, Jordan IK: Origin and evolution of human microRNAs from transposable elements. Genetics 2007, 176: I 323-1337.

12. Roman AC, Benitez DA, Carvajal-Gonzalez JM, Fernandez-Salguero PM: Genome-wide BI retrotransposon binds the transcription factors dioxin receptor and Slug and regulates gene expression in vivo. Proc Natl Acad Sci USA 2008, 105:1632-1637.

13. Thomas JW, Touchman JW, Blakesley RW, Bouffard GG, BeckstromSternberg SM, Margulies EH, Blanchette M, Siepel AC, Thomas PJ, McDowell JC, Maskeri B, Hansen NF, Schwartz MS, Weber RJ, Kent WJ, Karolchik D, Bruen TC, Bevan R, Cutler DJ, Schwartz S, Elnitski $L$, Idol JR, Prasad AB, Lee-Lin SQ, Maduro VV, Summers TJ, Portnoy ME, Dietrich NL, Akhter N, Ayele K, Benjamin B, Cariaga K, Brinkley CP, Brooks SY, Granite S, Guan X, Gupta J, Haghighi P, Ho SL, Huang MC, Karlins E, Laric PL, Legaspi R, Lim MJ, Maduro QL, Masiello CA, Mastrian SD, McCloskey JC, Pearson R, Stantripop S, Tiongson EE, Tran JT, Tsurgeon C, Vogt JL, Walker MA, Wetherby KD, Wiggins LS, Young AC, Zhang LH, Osoegawa K, Zhu B, Zhao B, Shu CL, De Jong PJ, Lawrence CE, Smit AF, Chakravarti A, Haussler D, Green P, Miller W, Green ED: Comparative analyses of multi-species sequences from targeted genomic regions. Nature 2003, 424:788-93

14. Bejerano G, Pheasant M, Makunin I, Stephen S, Kent WJ, Mattick JS, Haussler D: Ultraconserved elements in the human genome. Science 2004, 304: 1 32। - I 325

15. Woolfe A, Goodson M, Goode DK, Snell P, McEwen GK, Vavouri T, Smith SF, North P, Callaway H, Kelly K, Walter K, Abnizova I, Gilks
W, Edwards YJ, Cooke JE, Elgar G: Highly conserved non-coding sequences are associated with vertebrate development. PLOS Biol 2005, 3:e7.

16. Pang KC, Frith MC, Mattick JS: Rapid evolution of noncoding RNAs: lack of conservation does not mean lack of function. Trends Genet 2006, 22:I-5.

17. Vavouri T, Walter K, Gilks WR, Lehner B, Elgar G: Parallel evolution of conserved non-coding elements that target a common set of developmental regulatory genes from worms to humans. Genome Biol 2007, 8:RI5.

18. Taft RJ, Pheasant M, Mattick JS: The relationship between nonprotein coding DNA and eukaryotic complexity. Bioessays 2007, 29:288-299.

19. Straus NA: Comparative DNA renaturation kinetics in amphibians. Proc Natl Acad Sci USA I97I, 68:799-802.

20. Zhang ZD, Paccanaro A, Fu Y, Weissman S, Weng Z, Chang J, Snyder $M$, Gerstein MB: Statistical analysis of the genomic distribution and correlation of regulatory elements in the ENCODE regions. Genome Res 2007, 17:787-797.

21. Putta S, Smith J], Walker JA, Rondet M, Weisrock DW, Monaghan J, Samuels AK, Kump K, King DC, Maness NJ, Habermann B, Tanaka E, Bryant SV, Gardiner DM, Parichy DM, Voss SR: From biomedicine to natural history research: EST resources for ambystomatid salamanders. BMC Genomics 2004, 5:54.

22. Homo sapiens Genome: Statistics - Build 36 version I [http/ www.ncbi.nih.gov/mapview/stats/Build Stats. cgi?taxid $=9606 \&$ build $=36 \&$ ver $=1]$

23. Monaghan JR, Walker JA, Beachy CK, Voss SR: Microarray analysis of early gene expression during natural spinal cord regeneration in the salamander Ambystoma mexicanum. J Neurochem 2007, I 0 I:27-40

24. Page R, Monaghan JR, Samuels AK, Smith JJ, Beachy CK, Voss SR: Microarray analysis identifies keratin loci as sensitive biomarkers for thyroid hormone disruption in salamanders (Ambystoma). Comp Biochem Physiol Part C: Pharm and Tox 2007, 1 45: 15-27.

25. ORF Finder (Open Reading Frame Finder) [http:// www.ncbi.nlm.nih.gov/gorf/gorf.html]

26. Kozak M: Regulation of translation via mRNA structure in prokaryotes and eukaryotes. Gene 2005, 36 I:13-37.

27. Poulter R, Butler M: A retrotransposon family from the pufferfish (Fugu) Fugu rubripes. Gene 1998, 21 5:241-249.

28. Casimir CM, Gates PB, Ross-Macdonald PB, Jackson JF, Patient RK, Brockes JP: Structure and expression of a newt cardio-skeletal myosin gene: Implications for the $\mathbf{C}$ value paradox. I Mol Biol 1992, 202:287-296.

29. Morescalchi A, Serra V: DNA renaturation kinetics in some paedogenetic Urodeles. Experientia 1974, 30:49|-492

30. Hardison RC: Conserved noncoding sequences are reliable guides to regulatory elements. Trends Genet 2000, 16:369-372.

31. Jenuwien T, Allis CD: Translating the histone code. Science 200 I, 293:1074-1080

32. Mattick JS: RNA regulation: A new genetics? Nat Rev Genet 2004, 5:316-323.

33. Wendel JF, Cronn RC, Alvarez I, Liu B, Small RL, Senchina DS: Intron size variation in plants. Mol Biol Evol 2002, 19:2346-2352.

34. Grover CE, Kim H, Wing RA, Paterson AH, Wendel JF: Incongruent patterns of local and global genome size evolution in cotton. Genome Research 2004, 14:1474-I482.

35. Vinogradov AE: Intron-genome size relationship on a large evolutionary scale. J Mol Evol 1999, 49:376-384.

36. Deutsch M, Long M: Intron-exon structure of eukaryotic model organisms. Nucleic Acids Res 1999, 27:3219-3228.

37. Lynch M, Conery JS: The origins of genome complexity. Science 2003, 302: | $40|-| 404$.

38. Gao KQ, Shubin NH: Earliest crown group of salamanders. Nature 2003, 422:424-428.

39. Carroll RL: The Paleozoic ancestry of salamanders, frogs and caecilians. Zool J Linn Soc 2007, I 50(s I): I- | 40 .

40. Castillo-Davis Cl, Mekhedov Cl, Hartl DL, Koonin EV, Kondrashov FA: Selection for short introns in highly expressed genes. Nat Genet 2002, 31:203-207.

4I. Urrutia AO, Hurst LD: The signature of selection mediated by expression on human genes. Genome Res 2003, 13:2260-2264. 
42. Vinogradov AE: "Genome design" model: Evidence from conserved intronic sequence in human-mouse comparison. Genome Res 2007, 16:347-354.

43. Bryant SV, Hayamizu TF, Gardiner DM: Patterning in limbs: The resolution of positional confrontations. In Experimental and Theoretical Advances in Pattern Formation Edited by: Othermer HG, Maini PK, Murray JD. New York: Plenum; 1993:37-44.

44. Ohsugi K, Gardiner DM, Bryant SV: Cell cycle length affects gene expression and pattern formation in limbs. Dev Biol 1997 | 89:|3-2|.

45. Swinburne IA, Silver PA: Intron delays and transcriptional timing during development. Developmental Cell 2008, 14:324-330.

46. Vinogradov AE: Evolution of genome size: multilevel selection, mutation bias, or dynamic chaos? Curr Opin Gen Dev 2004, 14:620-626.

47. Monaghan JR, Walker JA, Beachy CK, Voss SR: Microarray analysis of early gene expression during natural spinal cord regeneration in the salamander Ambystoma mexicanum. J Neurochem 2007, 101:27-40.

48. Page R, Monaghan JR, Samuels AK, Smith J], Beachy CK, Voss SR Microarray analysis identifies keratin loci as sensitive biomarkers for thyroid hormone disruption in salamanders (Ambystoma). Comp Biochem Physiol Part C: Pharm and Tox 2007 145:15-27.

49. Cavalier-Smith T: Nuclear volume control by nucleoskeletal DNA, selection for cell volume and cell growth rate, and the solution of the C-value paradox. J Cell Sci 1978, 34:247-278.

50. Sessions SK, Larson A: Developmental correlates of genome size in Plethodontid salamanders and their implications for genome evolution. Evolution 1987, 41:|239-|25I.

51. Venter JC, Adams MD, Myers EW, Li PW, Mural RJ, Sutton GG, Smith HO, Yandell M, Evans CA, Holt RA, Gocayne JD, Amanatides P, Ballew RM, Huson DH, Wortman JR, Zhang Q, Kodira CD, Zheng XH, Chen L, Skupski M, Subramanian G, Thomas PD, Zhang J, Gabor Miklos GL, Nelson C, Broder S, Clark AG, Nadeau J, McKusick VA, Zinder N, Levine AJ, Roberts RJ, Simon M, Slayman C, Hunkapiller M, Bolanos R, Delcher A, Dew I, Fasulo D, Flanigan M, Florea L, Halpern A, Hannenhalli S, Kravitz S, Levy S, Mobarry C, Reinert K, Remington K, Abu-Threideh J, Beasley E, Biddick K, Bonazzi V, Brandon R, Cargill M, Chandramouliswaran I, Charlab R, Chaturvedi K, Deng Z, Di Francesco V, Dunn P, Eilbeck K, Evangelista C, Gabrielian AE, Gan W, Ge W, Gong F, Gu Z, Guan P, Heiman T], Higgins ME, Ji RR, Ke Z, Ketchum KA, Lai Z, Lei Y, Li Z, Li J, Liang Y, Lin X, Lu F, Merkulov GV, Milshina N, Moore HM, Naik AK, Narayan VA, Neelam B, Nusskern D, Rusch DB, Salzberg S, Shao W, Shue B, Sun J, Wang Z, Wang A, Wang X, Wang J, Wei M, Wides R, Xiao C, Yan C, Yao A, Ye J, Zhan M, Zhang W, Zhang H, Zhao Q, Zheng L, Zhong F, Zhong W, Zhu S, Zhao S, Gilbert D, Baumhueter S, Spier G, Carter C, Cravchik A, Woodage T, Ali F, An H, Awe A, Baldwin D, Baden H, Barnstead M, Barrow I, Beeson K, Busam D, Carver A, Center A, Cheng ML, Curry L, Danaher S, Davenport L, Desilets R, Dietz S, Dodson K, Doup L, Ferriera S, Garg N, Gluecksmann A, Hart B, Haynes J, Haynes C. Heiner C, Hladun S, Hostin D, Houck J, Howland T, Ibegwam C Johnson J, Kalush F, Kline L, Koduru S, Love A, Mann F, May D, McCawley S, McIntosh T, McMullen I, Moy M, Moy L, Murphy B, Nelson K, Pfannkoch C, Pratts E, Puri V, Qureshi H, Reardon M, Rodriguez R, Rogers $Y H$, Romblad D, Ruhfel B, Scott R, Sitter C, Smallwood M, Stewart E, Strong R, Suh E, Thomas R, Tint NN, Tse S, Vech C, Wang G, Wetter J, Williams S, Williams M, Windsor S, WinnDeen E, Wolfe K, Zaveri J, Zaveri K, Abril JF, Guigó R, Campbell MJ, Sjolander KV, Karlak B, Kejariwal A, Mi H, Lazareva B, Hatton T, Narechania A, Diemer K, Muruganujan A, Guo N, Sato S, Bafna V, Istrail S, Lippert R, Schwartz R, Walenz B, Yooseph S, Allen D, Basu A, Baxendale J, Blick L, Caminha M, Carnes-Stine J, Caulk P, Chians YH, Coyne M, Dahlke C, Mays A, Dombroski M, Donnelly M, Ely D, Esparham S, Fosler C, Gire H, Glanowski S, Glasser K, Glodek A, Gorokhov M, Graham K, Gropman B, Harris M, Heil J, Henderson S, Hoover J, Jennings D, Jordan C, Jordan J, Kasha J, Kagan L, Kraft C Levitsky A, Lewis M, Liu X, Lopez J, Ma D, Majoros W, McDaniel J, Murphy S, Newman M, Nguyen T, Nguyen N, Nodell M, Pan S, Peck J, Peterson M, Rowe W, Sanders R, Scott J, Simpson M, Smith T, Sprague A, Stockwell T, Turner R, Venter E, Wang M, Wen M, Wu $D$, Wu M, Xia A, Zandieh $A$, Zhu X: The sequence of the human genome. Science 200I, 291:1304-1351.

52. Di Palma F, Kidd C, Borowsky R, Kocher TD: Construction of bacterial artificial libraries for the Lake Malawi cichlid (Metria- clima zebra), and the blind cavefish (Astyanax mexicanus). Zebrafish 2007, 4:4I-47.

53. Green P: Phrap. 1994 [http://www.phrap.org/phredphrap consed.html].

54. Altschul SF, Gish W, Miller W, Myers EW, Lipman DJ: Basic local alignment search tool. J Mol Biol 1990, 21 5:403-4I0.

55. Smith JJ, Putta S, Walker JA, Kump DK, Samuels AK, Monaghan JR, Weisrock DW, Staben C, Voss SR: Sal-Site: Integrating new and existing ambystomatid salamander research and informational resources. BMC Genomics 2005, 6: I8I.

56. Pruitt KD, Tatusova T, Maglott DR: NCBI Reference Sequence (RefSeq): a curated non-redundant sequence database of genomes, transcripts and proteins. Nucleic Acids Res 2007, 35:D6I-65.

57. Kent WJ: BLAT - The BLAST-like alignment tool. Genome Res 2002, 1 2:656-664.

58. Rice P, Longden I, Bleasby A: EMBOSS: The European Molecular Biology Open Software Suite. Trends Genet 2000, 16:276-277.

59. Smit AFA, Hubley R, Green P: RepeatMasker Open-3.0. 1996 [http://www.repeatmasker.org].

60. Jurka J, Kapitonov VV, Pavlicek A, Klonowski P, Kohany O, Walichiewicz J: Repbase Update, a database of eukaryotic repetitive elements. Cytogenet Genome Res 2005, I I 0:462-467.

6I. Nam J-W, Kim J, Kim S-K, Zhang B-T: ProMiR II: a web server for the probabilistic prediction of clustered, nonclustered, conserved and nonconserved microRNAs. Nucleic Acids Res 2006, 34:W455-W458.

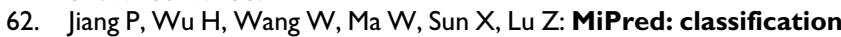
of real and pseudo microRNA precursors using random forest prediction model with combined features. Nucleic Acids Res 2007, 35:W339-W344.

63. Yang J-H, Zhang X-C, Huang Z-P, Zhou H, Huang M-B, Zhang S, Chen Y-Q, Qu L-H: snoSeeker: an advanced computational package for screening of guide and orphan snoRNA genes in the human genome. Nucleic Acids Res 2006, 34:5I I 2-5 I 23.

64. Kalyanaraman A, Aluru S, Kothari S, Brendel V: Efficient clustering of large EST data sets on parallel computers. Nucleic Acids Res 2003, 31:2963-2974.

65. Huang $X$, Madan A: CAP3: A DNA sequence assembly program. Genome Res 1999, 9:868-877.

66. Remm M, Storm CE, Sonnhammer EL: Automatic clustering of orthologs and in-paralogs from pairwise species comparisons. J Mol Biol 200I, 3 I 4: 104I-1052.

67. Goodstadt L, Ponting CP: Phylogenetic reconstruction of orthology, paralogy, and conserved synteny for dog and human. PLoS Comp Biol 2006, 2: I I34-I I 50.
Publish with BioMed Central and every scientist can read your work free of charge

"BioMed Central will be the most significant development for disseminating the results of biomedical research in our lifetime. "

Sir Paul Nurse, Cancer Research UK

Your research papers will be:

- available free of charge to the entire biomedical community

- peer reviewed and published immediately upon acceptance

- cited in PubMed and archived on PubMed Central

- yours - you keep the copyright
BioMedcentral 